\section{A TRADIÇÃO FILOSÓFICA E O PARADOXO DO FIM DO SUJEITO}

\author{
THE PHILOSOPHICAL TRADITION \\ AND THE PARADOX OF THE END OF THE SUBJECT
}

\author{
ROGÉRIO MIRANDA DE ALMEIDA ${ }^{1}$ \\ (PUCPR/Brasil)
}

\begin{abstract}
RESUMO
Estas reflexões têm como objetivo principal analisar a questão do fim do sujeito a partir da tradição filosófica ocidental. Assim, após uma breve introdução histórica que, partindo de Platão e passando por Aristóteles, Agostinho de Hipona e Tomás de Aquino, o texto se propõe examinar a questão do sujeito e da subjetividade na filosofia moderna e, principalmente, na filosofia contemporânea: Schopenhauer e Nietzsche. Com Freud e Lacan, é finalmente levada em consideração a problemática do fim do sujeito, que se exprime essencialmente como o paradoxo de uma exclusão interna. O sujeito da filosofia e da psicologia é, pois, ressignificado, reinterpretado e superado, mas a partir e através do próprio universo simbólico, no qual ele se move e do qual, paradoxalmente, ele se exclui.
\end{abstract}

PALAVRAS-CHAVE: Fim do sujeito; Schopenhauer; Nietzsche; Freud; Lacan.

\begin{abstract}
These reflections aim at analyzing the question of the end of subject from the Western philosophical tradition. Thus, after a brief historical introduction beginning from Plato and passing through Aristotle, Augustine of Hippo and Thomas Aquinas, the text intends to examine the question of subject and subjectivity in the modern and, principally, in the contemporary philosophy: Schopenhauer and Nietzsche. From the Freudian and Lacanian perspective, it will be taken more explicitly into consideration the problematic of the end of subject, which essentially expresses itself through the paradox of an internal exclusion. Therefore, the philosophical and psychological subject is revalued, reinterpreted and surpassed, but from and throughout the same symbolic universe, in which it moves itself and from which it paradoxically excludes itself.
\end{abstract}

KEYWORDS: End of subject; Schopenhauer; Nietzsche; Freud; Lacan.

Na concepção clássica filosófica que marcou a antiguidade clássica e a Idade Média, o sujeito não é descrito como uma entidade particularmente dotada da atividade mental que, a partir da filosofia moderna e, sobretudo, a partir de Descartes, receberá o nome de subjetividade. Em Platão e, mais precisamente, no Protágoras, o sujeito é o sujeito da predicação, na medida em que ele designa aquilo de que se predicam qualidades ou certas determinações (PLATÃO, 1977, 349b) $)^{2}$ No Teeteto, encontramos uma definição do pensamento, ou do ato de pensar que, sob vários aspectos, lembra a dinâmica da con-scientia entendida como um movimento de autorreflexão ou de diálogo que a alma mantém consigo mesma. Nesta perspectiva, quando a alma pensa, ela não faz outra coisa senão dialogar consigo mesma, na medida em que ela se interroga, responde, afirma e nega (PLATÃO, 1977, 189e-190a). Similarmente, Platão fará o Estrangeiro dizer a Teeteto, no Sofista, que o pensamento e a conversação em última instância 
se equivalem, embora o termo "pensamento" se aplique mais propriamente ao diálogo interior que, em silêncio, a alma desenrola consigo mesma. (PLATÃO, 1977, 263e).

Certo, em Platão, pode-se falar de um sujeito que tem consciência de sua autorreflexão ou, em outras palavras, de um sujeito que sabe do diálogo que desenvolve consigo mesmo. Mas como se apresenta o sujeito em Aristóteles? Para o Estagirita, o sujeito tem uma acepção não somente lógica, mas também ontológica, no sentido em que ele se dá como o suporte de que se predicam as coisas e, também, como o substrato ao qual inerem qualidades e determinações. Neste último sentido, o sujeito pode ser a matéria, por exemplo, o bronze, ou a forma, isto é, a configuração de que se reveste a matéria ou, ainda, o composto de matéria e forma (ARISTÓTELES, 1980, 1029a). Todavia, a representação do pensamento como uma dinâmica de diálogo da alma consigo mesma jamais poderia verificar-se de maneira preponderante num filósofo essencialmente empírico, como no caso de Aristóteles. É que a consciência das percepções sensíveis deve ser atribuída aos próprios sentidos e não a um sentido especial que, por assim dizer, reduplicaria os sentidos que percebem os objetos sensíveis. Se se devesse, pois, atribuir um sentido especial à consciência da percepção, dever-se-ia a fortiori pressupor um outro sentido especial para este último sentido, e assim ao infinito (ARISTÓTELES, 1975, 425b).

À diferença de Aristóteles, Agostinho de Hipona considera o sujeito como o sujeito da enunciação e da fé, pois, colocado diante de Deus, o homem pode enganar-se e duvidar de si próprio, mas, ao reconhecer-se pelo movimento da "iluminação interior" como um ser dotado dos vestígios da verdade, ou da Trindade divina, ele faz com que o sujeito advenha e, destarte, se afirme numa relação de liberdade face ao Outro. ${ }^{3}$ Consequentemente, o sujeito agostiniano se manifesta sob uma dupla modalidade: como o sujeito da enunciação que profere, declara, interroga e indaga, mas, por ser um sujeito que fala e, portanto, que crê, duvida, se examina e se engana, ele se coloca também no plano moral e religioso do dever. Efetivamente, na sua relação com o Outro, ele é constantemente admoestado sobre a obediência que deve à Lei, uma Lei que ele ama e que, ao mesmo tempo, deseja transgredir.

Na Alta Escolástica, e ao contrário do que se costuma afirmar, Tomás de Aquino fará ressaltar o papel da relação essencial que a mente estabelece consigo mesma através de uma dinâmica de diálogo ou de autorreflexão. Baseando-se em Agostinho de Hipona, o Aquinata declara que a nossa mente conhece a si mesma por si mesma, porquanto ela conhece, ou reconhece, a própria existência. Com efeito, percebendo a sua própria atividade, ela percebe também que existe (SAINT THOMAS AQUINAS, 1975, Book Three, Part I, Chapter 46, § 8). É bem verdade que, a partir desta passagem extraída da obra Suma contra os gentios, não se 
pode falar de um diálogo da alma consigo própria no mesmo sentido que lhe deram Platão e Agostinho. Ademais, conforme eu afirmei no início desta introdução, o conhecimento da mente por si mesma será um apanágio característico da subjetividade que se inaugura com os tempos modernos e, mais precisamente, com Descartes. Todavia, e é nisto que reside o ponto crucial das reflexões que serão aqui desenvolvidas: em que medida se pode dizer que o discurso filosófico tem-se revelado como uma contínua e sempre recomeçada tentativa de significar algo que escapa à significação como tal? Pois a significação - a partir e através da própria tensão fundamental do desejo - manifesta o discurso humano que sempre reenvia a outra significação.

Dados, porém, os limites formais deste estudo, eu me aterei mais particularmente à questão do sujeito tal como ele foi desenvolvido, articulado e significado nas filosofias moderna e contemporânea. Comecemos então por René Descartes (1596-1650).

\section{O sujeito na filosofia moderna e o paradoxo da certeza do eu pensante}

Descartes - baseado na representação das ideias claras e distintas - retoma o sujeito escolástico da enunciação para fundamentar o seu ideal de ciência epitomado na expressão: mathesis universalis. Mas com o primado da individualidade e da subjetividade - uma subjetividade de natureza racional - se eclipsa igualmente o sujeito social e político. Com o autor das Meditações, portanto, o sujeito se torna a própria consciência que, introspectivamente, toma a si mesma como objeto de indagação e de identificação. Trata-se do ato de um pensamento que, ao subsumir a reflexão, a vontade e a imaginação, considera-se a si mesmo como objeto, mas um objeto que, justamente, gira em torno de sua própria enunciação. Esta mesma enunciação é, segundo Heidegger, fundada sobre a representação ou, como elucida Jean-Paul Resweber: "O eu pensante é o que é somente porque ele se representa como dizendo aquilo que diz. Ele se vê ao se objetivar, e é esta objetivação que lhe fornece, em contrapartida, a base de sua identidade" (RESWEBER, 1990, p. 80).

A estrutura do sujeito cartesiano repousa, em última instância, sobre um fundamento ético que proporciona ao sujeito, a partir do interior, identificar-se com o gesto de uma intencionalidade constitutiva, expressa na própria enunciação. Caberá, pois, a Leibniz introduzir uma correção fundamental ao pensamento cartesiano, cujas consequências longínquas - com Brentano, Husserl, Sartre - serão a ênfase dada à exterioridade do sujeito, e não mais àquela consciência solitária com a qual Descartes o revestia. É também neste sentido que Immanuel Kant considerará a constituição do sujeito: a Lei como uma dupla dimensão da exterioridade e da alteridade, porquanto, analisada do ponto de vista teórico, a Lei, ou a razão, 
se volta para a exterioridade do em si, enquanto que, do ponto de vista prático, ela se manifesta como o fundamento do respeito que comanda as relações interpessoais e, consequentemente, os vínculos sociais. Simbolizando essa dupla orientação, a Lei transforma a abertura para uma realidade indefinida em um espaço e em uma dinâmica de decisão que o próprio sujeito, racionalmente, deve tomar (RESWEBER, 1990, p. 81).

Se agora voltarmos a Descartes, é-se primeiramente tentado a concluir - quando se considera o débito inconfessado do filósofo com relação a Agostinho - que o autor das Meditações não fizera outra coisa senão substituir o sujeito agostiniano da fé pelo sujeito da ciência. Na verdade, o deslocamento pelo qual o "cogito" emerge como a figura recapitulativa do ser é tributário não somente de Agostinho, mas também de toda a tradição agostiniana, na qual, direta ou indiretamente, velada ou deslavadamente, Descartes se inspirou. ${ }^{4}$ Neste sentido, convém antes de tudo ter presente que a condição para se obter a certeza - que é a fundamentação da ciência - passa necessariamente pela prova da existência de Deus, mesmo se esta prova tem como ponto de partida a própria consciência do cogito, ou do eu pensante. Forçoso, pois, é admitir que o sujeito cartesiano remete em última instância ao sujeito agostiniano da crença e da enunciação, conquanto esteja ele centrado sobre o eu pensante que, justamente, reenvia a uma transcendência divina, garantidora do saber. Com efeito, no tratado da Trindade, Agostinho afirma que Deus ou, mais exatamente, as três pessoas divinas se refletem e agem continuamente no movimento de interiorização da alma através das três faculdades: a memória, a inteligência e a vontade (AGOSTINHO DE HIPONA, 1973, XIV, 7, 10; XIV, 8, 11). Estas três faculdades são decerto distintas, mas elas não agem separadamente, porquanto, elucida o filósofo: "Eu me recordo de ter memória, inteligência e vontade. Eu entendo que entendo, que quero e que me recordo. Tenho vontade de querer, de recordar, de entender" (AGOSTINHO DE HIPONA, 1973, X, 11, 18). Segundo Agostinho, tão imediato e seguro é o conhecimento que o espírito tem de si mesmo, que a ele nada acrescentamos quando ouvimos a voz do preceito: "conhece-te a ti mesmo". De fato, ajunta o teólogo:

O espírito sabe com certeza que esse preceito é dirigido a ele, a ele que existe, que vive, que compreende. Mas o cadáver também existe, os animais também vivem: todavia, nem o cadáver, nem os animais compreendem. $\mathrm{O}$ espírito, porém, sabe que existe e que vive do mesmo modo como existe e vive a inteligência (AGOSTINHO DE HIPONA, 1973, X, 10, 13).

Se, portanto, a questão do sujeito em Agostinho e Descartes se coloca ao nível da enunciação, da fé e da dúvida, como então se exprime o sujeito na filosofia contemporânea e, particularmente, no pensamento de Schopenhauer e de Nietzsche? 


\section{O sujeito na filosofia contemporânea: Schopenhauer e a vontade}

Convém antes de tudo notar que, em Schopenhauer, sujeito e objeto literalmente se confundem no movimento da representação. "Não partimos - declara o filósofo - nem do objeto nem do sujeito, mas da representação que os contém e os pressupõe a ambos" (SCHOPENHAUER, 2004, p. 59). Melhor ainda: tudo aquilo que o mundo encerra depende inevitavelmente do sujeito, mas do sujeito da representação. Por conseguinte, tudo o que existe não existe senão para o sujeito, pois “todo este mundo não é outra coisa senão objeto em relação ao sujeito" (SCHOPENHAUER, 2004, p. 31). O próprio sujeito, no entanto, se revela irrepresentável, pois: “Aquilo que a tudo conhece, sem ser ele próprio conhecido por qualquer outra coisa, é o sujeito. O sujeito é, portanto, o suporte do mundo, a condição universal, sempre pressuposta, de todo fenômeno, de todo objeto: de fato, tudo o que existe não existe senão para o sujeito" (SCHOPENHAUER, 2004, p. 33, grifo nosso).

Ora, a essência mais íntima deste fenômeno que se manifesta como representação é a vontade. Na vontade, diz Schopenhauer, não se podem mais nitidamente distinguir nem sujeito nem objeto, porquanto ela mesma não se deixa conhecer na sua universalidade, mas tãosomente nos seus fenômenos, ou seja, nas ações singulares dos indivíduos e, principalmente, através de seu substrato permanente, que é o corpo. Assim, esta essência íntima de toda a natureza tem, na perspectiva de Schopenhauer, uma abrangência cósmica, metafisica, universal. Ela se manifesta na força que faz crescer e vegetar a planta, na impulsão que dá forma ao cristal e que dirige a agulha magnetizada para o Polo Norte, no choque que acarreta o contato de dois metais heterogêneos, nas afinidades eletivas dos corpos sob a dinâmica da repulsão e da atração, da combinação e da decomposição; ela se manifesta, em suma, na gravidade que age com uma incalculável potência sobre toda a matéria, atraindo a pedra para a terra e a terra para o céu (SCHOPENHAUER, 2004, p. 170). A tensão que caracteriza essa vontade não conhece, pois, nem saciedade nem fim. É o que assevera enfaticamente o filósofo:

Todo fim alcançado não faz senão marcar o ponto de partida de uma nova meta a ser atingida, e assim ao infinito. (...) Um eterno vir-a-ser e um infindável fluir são a manifestação da essência da vontade. O mesmo se revela nos esforços e nos desejos humanos, que fazem brilhar diante de nós a sua satisfação como sendo o alvo último da vontade. Uma vez, porém, satisfeitos, não mais se assemelham ao que eram antes e, portanto, são logo esquecidos ou relegados como antiqualhas e, admita-se ou não, são sempre postos de lado como ilusões que se dissiparam (SCHOPENHAUER, 2004, pp. 240-241). 
Se se pode, pois, falar de um fim do sujeito em Schopenhauer, este residiria na tensão do desejo, ou da vontade, que não cessa de terminar e de recomeçar, de se descarregar e de se repletar, de se saciar e de querer mais. Esta é a razão pela qual o filósofo é tão categórico ao afirmar:

Todo querer (Wollen) se origina de uma necessidade (Bedürfnis), isto é, de uma privação e, portanto, de um sofrimento. Neste, a realização (Erfüllung) vem colocar um termo. Todavia, para realizar um desejo (Wunsch), pelo menos dez outros desejos devem ser contrariados. Além do mais, o desejo (Begehren) parece ter uma duração ilimitada, e as suas exigências tendem ao infinito (SCHOPENHAUER, 2004, pp. 279).

É bem verdade que os atos isolados da vontade têm um objetivo preciso, na medida em que esta mesma vontade é iluminada pelo conhecimento em um determinado momento e em um determinado lugar. Considerada, porém, na sua universalidade ou na sua essência, a vontade - ou o desejo - não tem nenhum objetivo determinado ou nenhuma meta que possa ser alcançada de uma vez por todas. O paradoxo da vontade schopenhaueriana consiste, pois, em que a sua finalidade - se é que de uma finalidade se pode aqui falar - está na sua infinita insaciabilidade e implacabilidade. Daí também poder-se compreender o reconhecimento de Freud vis-à-vis do solitário de Frankfurt como um dos precursores da teoria analítica, particularmente no que diz respeito ao universo das pulsões. Efetivamente, ao referir-se ao filósofo, Freud chama-o de "o grande pensador Schopenhauer, cuja 'vontade' inconsciente pode ser comparada às pulsões psíquicas de que fala a psicanálise” (FREUD, 1999, XII, p. 2). É que, também na perspectiva de Freud, a satisfação sempre pressupõe um objeto, mas todo objeto é parcial, porque parciais são também as pulsões no seu eterno desenrolar-se e no seu perpétuo saciar-se.

É lícito, pois, afirmar que os conceitos de pulsão em Freud, de vontade em Schopenhauer e, como veremos a seguir, de vontade de potência em Nietzsche coincidem da maneira mais surpreendente. Com efeito, para estes três pensadores, a infinita satisfação-insatisfação que se desdobra e se desloca no interior do sujeito se caracteriza essencialmente por uma falta, uma lacuna e uma hiância que a tensão do desejo não cessa de manifestar. ${ }^{5}$ Convém, no entanto, relevar que se, em Schopenhauer, o que está em jogo é a subsunção e abolição do indivíduo enquanto fenômeno no seio mesmo do querer universal, em Nietzsche o fim do sujeito também se inscreve no movimento essencial da vontade, mas uma vontade que o filósofo considera como sendo vontade de potência. 


\section{Nietzsche: o sujeito e a vontade de potência}

Efetivamente, o universo nietzschiano da vontade se desenrola, essencial e continuamente, como uma tendência para mais potência, ou para o acúmulo de mais potência, porquanto o elemento que constitui o núcleo ou o mais íntimo de todo ser não é, segundo Nietzsche, a conservação nem a autoconservação, mas a acumulação máxima de força, de apropriação, de dominação e incorporação. Esta é a razão pela qual, no discípulo de Dioniso, a vontade de potência, a interpretação e a questão do sujeito - ou do fim do sujeito - estão intrinsecamente ligadas entre si. Afinal de contas, quem interpreta, senão um sujeito que fala e, portanto, significa, denomina e simboliza a partir e através de uma imbricação e de um entrelaçamento de pulsões que, elas mesmas, não cessam de se significar e de se superar, mas na repetição e na diferença. Daí indignar-se Nietzsche contra todos aqueles que se perguntam: “Quem, pois, interpreta?”. Ora, o próprio interpretar já é, na perspectiva da vontade de potência, uma forma que existe não como ser (Sein), mas como processo, como afeto, como pathos, como vir-a-ser (NIETZSCHE, 1999, 12, p. 140). Interpretar é, portanto, reinterpretar ou, mais exatamente, tornar-se senhor de alguma coisa, impor-lhe um novo nome e, consequentemente, um novo sentido. Interpretar é, em suma, apoderar-se das coisas através de um contínuo e interminável plasmar, remodelar, reinventar e recriar. É, pois, assim que se exprime o filósofo num texto de outono 1885-outono 1886 :

Interpretação, não explicação. Não há nenhum estado de fato, tudo é fluido, inapreensível, evanescente; o que há de mais duradouro são ainda as nossas opiniões. Colocar um sentido - na maioria dos casos, uma nova interpretação sobre uma velha interpretação que se tornou incompreensível e que agora é somente signo (NIETZSCHE, 1999, 12, p. 100).

Multiplicidade de perspectivas e de sentidos é, portanto, o leitmotiv que atravessa e pontilha todos os escritos e, por conseguinte, todo o pensamento do discípulo de Dioniso. Em última instância, não há nenhum sentido em si, nenhuma interpretação em si, nenhum valor em si. Existem antes forças que comandam e forças que obedecem, forças que constroem e forças que destroem, forças que aniquilam e forças que recriam. Assim, ao invés de se interrogar pelos valores que estão em voga, urge em primeiro lugar indagar-se pelas forças e as relações de forças que estão na base da criação e da imposição de novas tábuas de valores. ${ }^{6}$ Com efeito, reivindicar uma interpretação "em si" redundaria na necessidade de primeiramente se obter uma explicação do que seria este “em si”. Ora, na visão de Nietzsche - nunca é demasiado enfatizar - toda interpretação já pressupõe uma força ou relações de forças que interpretam, que se 
superam, que se ultrapassam e constantemente se recriam. Daí podermos melhor entender a veemência com a qual o filósofo investe contra toda tentativa positivista de reduzir a realidade a fenômenos e, deste modo, reivindicar a concepção segundo a qual haveria "somente fatos":

\begin{abstract}
Não, justamente não há fatos, mas somente interpretações. Não podemos constatar nenhum factum "em si": é talvez um contrassenso querer este tipo de coisa. "Tudo é subjetivo", direis vós: mas isto já é uma interpretação. O "sujeito" não é um dado de fato, mas algo que se ajuntou com a imaginação, que se colocou depois. -É finalmente necessário colocar ainda o intérprete atrás da interpretação? Mas isto já é invenção, hipótese.

Na medida em que a palavra "conhecimento" tem um sentido, o mundo é conhecível: mas ele é interpretável de diversos modos, não tem nenhum sentido atrás de si, mas inúmeros sentidos: "perspectivismo" (NIETZSCHE, 1999, 12, p. 315, grifo nosso).
\end{abstract}

Por conseguinte, a interpretação em Nietzsche reenvia a um sujeito que se exprime como ficção, como ilusão, como arte, como invenção poética e, em suma, como vontade de enganar e de ser enganado. “O 'sujeito' - dirá o filósofo num fragmento póstumo de outono 1887 - é tão somente uma ficção: o ego de que se fala quando se critica o egoísmo não existe de forma alguma" (NIETZSCHE, 1999, 12, p. 398). E, de fato, assim como se poderia reivindicar, para cada interpretação, a preexistência de um sujeito que lhe fosse necessariamente inerente, do mesmo modo se poderia pressupor a existência de outro sujeito para este último sujeito, e assim ao infinito. Ora, o sujeito nietzschiano é sujeito na medida mesma em que ele manifesta ou se manifesta através de um pulular de forças e de relações de forças que não cessam de se incluir e de se excluir, de se superar e de se recriar, de se repetir e de recomeçar, mas na diferença e no querer-mais.

A conclusão, pois, não poderia ser outra: o fim do sujeito no pensador da vontade de potência consiste em que a saciedade do desejo, ou da vontade, reside paradoxalmente na sua contínua satisfação e insatisfação, ou no seu eterno aplacar-se e querer-mais. Se, portanto, em Schopenhauer, a vontade, o desejo e, em última análise, o sujeito é ambíguo na medida em que ele se afirma e se nega ao mesmo tempo; se, em Nietzsche, a vontade e, consequentemente, o sujeito se manifesta pela superabundância de vida, de seiva, de força, mas também pela tendência a aniquilar e a destruir, em Freud e em Lacan o sujeito se exprime principalmente conforme veremos mais abaixo - pela fala e, portanto, pela falta, a hiância, a significação e a simbolização. Mas uma simbolização que também não cessa de terminar e de recomeçar, porque as pulsões que animam o desejo - e que se situam no limite do psíquico e do somático - requerem outro tipo de alimento. Não se trata de um alimento sólido ou líquido, como para o instinto, mas antes de um alimento que venha satisfazer um pedido de amor e que se articula 
pela significação, a simbolização, a denominação ou, em suma, a linguagem. Em que, pois, consiste o fim do sujeito para a psicanálise, e para Freud em particular?

\section{Freud e as três ofensas ao narcisismo universal}

Num artigo intitulado: Uma dificuldade da psicanálise, escrito em 1916 e publicado no ano seguinte pela revista Nyugat, de Budapest, Freud analisa aquilo que ele denomina as três graves humilhações ou ofensas (Kränkungen) que a pesquisa cientifica infligiu ao narcisismo da humanidade. Trata-se de uma humilhação de ordem cosmológica, de ordem biológica e, finalmente, de ordem psicológica (FREUD, 1999, XII, pp. 3-12) ${ }^{7}$ Antes, porém, de começar a descrever essas três humilhações, o inventor da psicanálise destaca as descobertas que, até aquele momento, lhe haviam propiciado a teoria e a prática analíticas. Primeiramente, diz ele ter adotado para a elaboração das duas pulsões principais - as pulsões de conservação do eu e as pulsões que impelem o organismo a reproduzir-se - a representação popular segundo a qual nós somos movidos pela fome e pelo amor. Curiosamente, ao definir a libido como sendo a energia com a qual as pulsões sexuais se manifestam na vida psíquica, ele a denomina "vontade de potência" (Machtwillen). Em seguida, chama a atenção para o papel do trabalho terapêutico que consiste, precisamente, em ajudar o analisando a equilibrar a distribuição ou repartição da energia libidinal. É que - pondera Freud - no início do desenvolvimento do indivíduo, toda a libido que investe eroticamente o eu está essencialmente ligada à própria pessoa. Somente mais tarde é que, em virtude das grandes necessidades da existência, essa energia desborda do eu, dirige-se para os objetos externos, possibilitando assim distinguir mais nitidamente as pulsões sexuais daquelas do eu. Ocorre, porém, que a libido pode novamente desvincular-se dos objetos externos e, mais uma vez, retornar para dentro do eu (FREUD, 1999, XII, p. 3-5). Esta dinâmica, Freud a designa pelo nome de narcisismo, inspirado, como se sabe, na lenda do jovem Narciso que, segundo uma das versões do mito, teria ido desalterar sua sede às margens de uma fonte, na qual ele via refletida a beleza do próprio rosto. Tomado de amor por esta visão que ele não conseguia alcançar, justamente por não poder desvencilhar-se da própria imagem, Narciso teria negligenciado o beber e o comer, de modo que, ao criar raízes à borda do manancial, ter-se-ia paulatinamente transformado na flor que hoje traz o seu nome. Desde então, diz o mito, esta flor se reflete na água durante a bela estação e deperece com o retorno do outono.

$\mathrm{Na}$ minha perspectiva, este texto de 1916 forma, juntamente com os outros escritos do mesmo período - por exemplo, Introdução ao narcisismo (1914) - aquilo que eu considero como sendo a fase de transição do inventor da psicanálise. Ele se situa, portanto, entre o 
primeiro período - caracterizado pela ênfase dada ao binômio princípio do prazer e princípio da realidade - e o terceiro período, cujo acento se deslocará, principalmente a partir de 1920, para um além do princípio de prazer. Neste escrito de transição (Uma dificuldade da psicanálise), Freud pondera a possibilidade de o indivíduo passar do narcisismo para o amor objetal, conquanto a libido jamais consiga transvasar totalmente do $e u$ para os objetos externos. Pois determinado teor libidinal sempre permanecerá no eu e, consequentemente, um resto de narcisismo sempre persistirá no sujeito, por mais que o amor objetal nele se ache desenvolvido. Donde a frase lapidar com a qual Freud sintetiza essa nova teoria: "O eu é um grande reservatório de onde deflui a libido destinada aos objetos e para onde ela torna a refluir" (FREUD, 1999, XII, p. 6). Não obstante isso, o inventor da psicanálise enfatiza que é fundamental para a completa sanidade dos indivíduos que a libido não perca esta capacidade de mobilidade que se instaura entre o $e u$ e os objetos que o rodeiam. Convém também acentuar que os pressupostos teóricos deste conceito se aplicam igualmente ao comportamento das pessoas ditas "normais". Não menos curiosa é a comparação que Freud efetua entre o narcisismo da criança e o excesso de narcisismo que, segundo ele, caracterizava o homem primitivo. Este, diz Freud, parecia crer na onipotência de seus pensamentos a ponto de querer influir sobre o curso dos acontecimentos do mundo externo mediante as técnicas da magia (FREUD, 1999, XII, p. 6). Mas, para voltarmos ao tema principal desta seção, quais são propriamente as três graves ofensas que sofreu o amor-próprio da humanidade em virtude do desenvolvimento da ciência?

a) A primeira ofensa ocorreu, consoante Freud, na primeira metade do século XVI, com a teoria heliocêntrica de Copérnico. Sabe-se, com efeito, que é atribuído ao astrônomo polonês, Nicolau Copérnico (1473-1543), o mérito de haver iniciado, ou fundado, a astronomia moderna. No seu De revolutionibus orbium coelestium (1543), Copérnico introduziu uma importante reforma na antiga astronomia ptolomaica, reforma esta que veio substituir o modelo do universo centrado sobre a Terra (geocentrismo) pelo novo modelo, justamente chamado heliocentrismo. Com esta revolução, o astrônomo polonês teria não somente destronado a terra do centro do universo, mas também - o que parece ser o mais importante - mudado a visão do homem sobre si mesmo e sobre a existência em geral. É que a crença na posição central da Terra, inferida ingenuamente a partir da percepção que se tem da abóbada celeste, se apresentava como capaz de garantir o papel de dominação que o homem exercia, ou acreditava exercer, sobre o universo. Ora, a destruição de semelhante ilusão teria vindo infligir, segundo Freud, um golpe, uma humilhação, ou uma ofensa ao interior do narcisismo ou do amor próprio da humanidade. Esta seria, pois, uma ofensa de ordem cosmológica (FREUD, 1999, XII, p.7). 
b) A segunda ofensa sobreveio em meados do século XIX, graças às teorias e experiências desenvolvidas por Charles Darwin e seus colaboradores sobre a origem das espécies e, particularmente, sobre a ascendência do homem. Certo, antes mesmo de Darwin publicar a Origem das espécies por via da seleção natural (1859), já circulavam ideias sobre as mudanças, as transformações e modificações no seio da natureza que não necessitavam de fazer apelo a uma intervenção sobrenatural, exterior e transcendente à sua própria dinâmica. Dentre os defensores destas ideias se destacava o naturalista francês Lamarck, a quem Darwin criticava e, ao mesmo tempo, reconhecia seu pioneirismo. Ora, ao evocar essas pesquisas, e aquelas de Darwin em particular, Freud quer chamar a atenção para o fato de terem elas infligido um violento golpe à pretensão de o homem considerar-se oriundo de uma estirpe nobre, divina, que teria sido plasmada, modelada e saída diretamente das mãos do Criador. Ao concordar com as ideias de Darwin, Freud também quer enfatizar que o homem, quanto à sua ascendência, em nada difere do restante dos animais, porquanto ele também provém da mesma série animal e mostra evidentes traços de parentesco, ora em maior, ora em menor escala, com relação às demais espécies animais. Consequentemente, as suas sucessivas aquisições culturais em nada lhe permitem abolir as características de uma paridade que se manifesta tanto na sua estrutura biológica, isto é, corpórea, quanto na sua disposição psíquica (FREUD, 1999, XII, p. 8). Assim, segundo Freud, a teoria da seleção natural desenvolvida por Darwin desferiu um segundo golpe ou uma segunda humilhação ao narcisismo universal da humanidade. Esta foi uma humilhação, ou uma ofensa, de ordem biológica.

c) A terceira ofensa, considerada como a mais rica em consequências para a civilização, sobreveio, segundo Freud, com o nascimento e desenvolvimento da psicanálise. Ao analisar esta última humilhação, Freud evoca a formação da consciência, que a tradição filosóficopsicológica via como a instância central do ego e pela qual o homem desenvolvera a capacidade de observar e controlar, até certo ponto, seus impulsos e suas ações. Se, pois, estes impulsos e estas ações se harmonizassem com as exigências da consciência, eles estariam aptos a receberem seu beneplácito e sua sanção. Caso contrário, seriam implacavelmente inibidos ou afastados como indesejáveis. Havia como que uma percepção interna encarregada de transmitir ao ego tudo aquilo de importante que se desenrolasse nas operações da mente, de modo que a vontade, dirigida por essas informações, realizaria o que o eu lhe ordenava fazer. Inversamente, as afecções que procurassem impor-se independentemente do eu seriam ipso facto modificadas ou, se possível, eliminadas (FREUD, 1999, XII, p. 9). No entanto, a psicanálise veio mostrar que, por mais que o eu se sinta "soberano na própria psique", há determinadas neuroses que o levam a embater-se contra dificuldades e resistências, cuja proveniência ele ignora e cuja 
potência não se deixa dobrar por nenhum raciocínio ou refutação lógica. Trata-se efetivamente de forças ou de pulsões que se manifestam - apesar do sujeito - através dos atos falhos e de todos aqueles sintomas mediante os quais o corpo fala à maneira de um texto que deve ser decifrado, interpretado, analisado.

Ademais, a reestruturação do aparelho psíquico que este escrito de 1916 já nos faz antever, será plenamente desenvolvida, ampliada e explicitada no estudo de 1923, intitulado: Das Ich und das Es (O ego e o id). Nesta obra que, por assim dizer, prolonga, amplia e aprofunda o Além do princípio de prazer (1920), o inventor da psicanálise chega à conclusão de que a verdadeira questão não mais consiste em reduzir a neurose a um conflito entre o consciente e o inconsciente ou, em outros termos, entre um $e u$ pretensamente harmonioso e coeso e o mundo inconsciente das pulsões e da libido. É que a experiência analítica descobrira que existem também no eu elementos inconscientes e que ele se comporta como tendo sido também recalcado. Urgia, pois, substituir esta oposição por outra mais originária e mais primordial ainda: de um lado, o eu supostamente coerente e unitário e, de outro, o processo de recalcamento que dele se distingue e, ao mesmo tempo, está com ele intrinsecamente relacionado (FREUD, 1999, XIII, p. 244). Consequentemente, convinha agora considerar uma dinâmica de pulsões e uma economia libidinal que, sem cessar, interferem simultaneamente nas três instâncias do aparelho psíquico: o $\mathrm{eu}$, que a psicologia clássica retinha como sendo o núcleo da coerência e da harmonia do sujeito; o supereu, que é a instância da censura e das interdições; e o isso que, do ponto de vista econômico, se apresenta como o reservatório primário da libido e, dinamicamente, como o polo pulsional que entra em conflito com o eu e o supereu (FREUD, 1999, XIII, p. 244). ${ }^{8}$

Assim, ao mostrar em plena luz o jogo de forças ou de pulsões que subjazem às formações psíquicas, a experiência analítica vem também revelar que o eu é, finalmente, um pobre eu. Efetivamente, se, de um lado, ele se embate constantemente contra o isso e o supereu, de outro, ele procura fazer as pazes com ambas as instâncias e, deste modo, satisfazer as exigências incondicionais do desejo e os mandamentos daquilo que a tradição cristã chamava de "consciência moral" e Immanuel Kant de imperativo categórico.

Isto nos faz lembrar as três conferências que Lacan proferiu na capela do hospital SainteAnne, entre o final de 1971 e o início de 1972, e que depois foram publicadas sob o título geral: Je parle aux murs (Falo às paredes). É justamente na conferência de número 3, especificamente intitulada Je parle aux murs, que Lacan afirma que o mestre do jogo é sempre o significante e que o sujeito não é, afinal de contas, senão um suposto sujeito com relação a algo que é outro (autre), para não dizer o Outro (Autre). Este Autre, da ordem da linguagem e da cultura, que se 
apresenta como o nome-do-pai (Nom-du-Père), vale dizer, como o garantidor da lei e da promessa do desejo, é na verdade o significante. Ele é, em outras palavras, o lugar da alteridade e do reconhecimento de si que nunca é alcançado, nunca é realizado, porque nunca suficientemente articulado. Segundo Lacan, nós não damos sentido a este Autre, na medida em que nós mesmos não o temos bastante para dar. Todavia, conclui o pensador: "Mas vocês lhe dão um corpo, a este significante que os representa, isto é, o significante-mestre" (LACAN, 2011, p. 105).

Feitas estas considerações em torno da questão do sujeito na perspectiva da tradição filosófico-psicológica e naquela de Freud, é-nos agora lícito indagar por este mesmo sujeito na concepção ao mesmo tempo de Freud e de Jacques Lacan. Afinal de contas, de que sujeito propriamente se trata quando se consideram estes dois pensadores? Estaria ele totalmente liberto, isento, imune, das elaborações e reelaborações que sobre ele efetuou a tradição filosófica, ou reenviaria ele ainda àquela mesma tradição e, mais particularmente, à filosofia de Descartes e às consequências que dela derivam?

\section{A psicanálise: um novo mergulho no sujeito cartesiano?}

Segundo Lacan, a importância da descoberta de Freud reside justamente no descentramento ou na heterogeneidade do sujeito com relação ao $e u$, que a linguagem não cessa de exprimir, de significar e simbolizar. Nesta perspectiva, o sujeito só é sujeito na medida em que ele, ou melhor, em que isso (o inconsciente) fala e, por conseguinte, trai, esconde e revela. É que, ao se manifestar a partir de uma tensão - que é a tensão do desejo na sua insaciabilidade fundamental - o sujeito está continuamente a apontar para uma perda originária, para um recalque originário e, logo, para uma angústia da castração que, ela também, não cessa de se nomear, de se designar, de se interpretar, de se reinterpretar e, portanto, de se dizer e se desdizer. Donde o gozo fálico do ainda não: ainda não dito, ainda não escrito, ainda não falado, ainda não completado, ainda não arrematado, ainda não terminado e, consequentemente, ainda não completamente gozado. É, pois, nesta defasagem ontológica, ou pré-ontológica, entre o significante e o significado - ou entre o já dito e aquele pequeno resto que permanece em suspenso - que a tensão do sujeito e, em última análise, do desejo não cessa de se satisfazer, de se colmatar, de se repletar, de se aplacar e, ao mesmo tempo, de querer mais. Para Lacan, portanto: "Essa hiância inscrita no status mesmo do gozo como di-mensão do corpo, no ser falante, é o que ressurge com Freud através deste teste - nada mais acrescento - que é a existência da palavra. Lá onde se fala, goza-se” (LACAN, 1975, p. 104, grifo nosso). E 
poderíamos ajuntar: lá onde há interdito e, portanto, resistência, existem também desejo e angústia. Todo desejo é acompanhado de angústia, mas não esqueçamos de que a angústia faz gozar.

A reinterpretação original que operou Lacan com relação às descobertas de Freud consiste, pois, em ter o analista francês colocado o problema da linguagem, do discurso e, portanto, do desejo no centro mesmo de sua teoria e de sua prática analítica. Ao examinar o discurso do delirante no Seminário III, Sobre as psicoses, Lacan chama a atenção para o fato de existir, no sentido vertical, o registro do sujeito, da palavra e da ordem da alteridade como tal, ou seja, o Outro. Todavia, ele vai mais longe ainda ao enfatizar que o foco ou o pivô mesmo da função da palavra é a subjetividade do Outro. Mas em que sentido? No sentido em que o Outro, como sujeito, é essencialmente capaz de convencer, mas também de mentir, de enganar, de ludibriar e, portanto, de subtrair-se à demanda e, em última análise, ao desejo daquele que lhe dirige a palavra. Porém, algo deve existir que não pode enganar. Com efeito, pondera Lacan: "O correlato dialético da estrutura fundamental que faz da palavra de sujeito a sujeito uma palavra que pode enganar é que haja também algo que não engane" (LACAN, 1981, p. 76).

Ora, para se entender a dinâmica do desejo, tal como Lacan a reelaborou, convém primeiramente fazer uma distinção capital entre a necessidade (besoin) e o pedido (demande). A necessidade, que remete ao biológico e ao instintual, visa um objeto determinado e com ele se satisfaz, por exemplo, a fome com o alimento, a sede com o líquido, o cansaço com o sono, etc. Uma vez aplacado o estímulo, o ciclo estará mais uma vez apto a começar tudo de novo, mas ele o fará segundo uma ordem, uma regularidade e um ritmo característico do próprio organismo. Com relação ao pedido, porém, as coisas se passam de maneira totalmente diferente, na medida em que se trata aqui de uma falta que deve ser expressa, ou melhor, falada, articulada, simbolizada e significada. Para dizê-lo de outro modo, o pedido não está ligado à esfera do instintual ou do orgânico, mas à das pulsões, ou daquelas forças constantes cujas expressões, ao articularem o psíquico e o somático, não conhecem - diz Lacan - nem dia nem noite, nem primavera nem outono, nem subida nem descida (LACAN, 1973, p. 150). Esta diferença fundamental entre o instinto e a pulsão foi lucidamente resumida por Roland Sublon quando descreve a dinâmica do inútil que, através das pulsões, se repete indefinidamente e independentemente de toda finalidade, de todo cálculo e de todo gerenciamento possível do binômio prazer-desprazer: 
Para satisfazer o instinto, necessita-se de algo sólido. A pulsão, ao invés, quer sonho, porquanto o objeto da necessidade (besoin) não pode satisfazê-la. E por quê? Porque o prazer que rege o inconsciente é prazer do retorno: prazer do reencontro, prazer que oferece o objeto marcado pelo mesmo traço e pelo mesmo punção que, outrora, viera satisfazer: retorno do mesmo. Repetição. A satisfação passa, portanto, por um objeto, não importa que tipo de objeto; todavia, este objeto só vale enquanto representa. Ele vale por aquilo que ele representa, para quem ele representa. O objeto da pulsão que deveria satisfazer é, pois, aquele mesmo que, um dia, viera trazer, revelar outra coisa. Este objeto tornou-se em seguida um objeto primeiro; primeiro, porque uma segunda satisfação veio elevá-lo a esta ordem - impossível - de um perfeito padrão que, doravante, denuncia qualquer outro gozo incapaz de atingir este modelo perdido (SUBLON, 1993, p. 220).

Esta diferença que marca radicalmente o instintual e o pulsional, Freud também já a havia detectado ao reelaborar a teoria das pulsões naquele ensaio de 1915, intitulado: Pulsões e destino das pulsões. Neste escrito, depois de denominar a pulsão um "conceito fundamental convencional", o inventor da psicanálise ajunta-lhe também o adjetivo "constante". Assim, a pulsão se caracteriza como sendo essencialmente uma "força constante" que, ao contrário dos outros estímulos fisiológicos, ataca não a partir do exterior, mas de dentro do próprio corpo. Ela é, pois, "um conceito-limite entre o psíquico e o somático", que age como um representante psíquico dos estímulos provenientes do interior do corpo e que alcança a mente como uma medida da exigência do trabalho psíquico. Mas este trabalho só lhe é imposto porque existe um vínculo, uma passagem, uma ponte ou um entre-dois ligando o psíquico e o somático (FREUD, 1999, X, pp. 211-214). Estamos, portanto, colocados no nível do simbólico - e do inconsciente - em que o sujeito age apesar dele próprio, ou seja, sem conhecer, o mais das vezes, as razões pelas quais ele age, justamente porque age de maneira inconsciente. Na verdade, o inconsciente não conhece nem tempo nem contradição e, assim, ele se manifesta à maneira de uma instância acefálica que fala do sujeito, malgré lui. Enquanto sujeito ético da ação, ele deve constantemente responder pelo seu próprio desejo e, consequentemente, pelos seus sonhos, pelos seus atos falhos e pelas outras incongruências do discurso que escapam ao domínio da consciência e, portanto, da arte do bem pensar, do bem falar ou, numa palavra, do saber policiarse. ${ }^{9}$

Curiosamente, o consciente é o caminho pelo qual se chega ao inconsciente, porquanto é graças ao trabalho analítico, observa Freud, que o inconsciente se revela - e se esconde ao mesmo tempo - através dos meandros, das transposições e deformações que ele sofreu na esfera do consciente. Certo, o inconsciente permanece inconsciente, todavia, o sujeito tenta simbolizar, integrar e, logo, traduzir e superar aquelas resistências que, em sua época, foram responsáveis pelo recalcamento das respectivas representações (FREUD, 1999, XIII, p. 264). De resto, não é por acaso que Freud designa os conteúdos do inconsciente pela expressão 
“representantes da pulsão", pois, estando situada no entre-dois do psíquico e do somático, a pulsão jamais poderá tornar-se objeto da consciência, achando-se presente no inconsciente somente através de seus representantes, ou seja, daqueles elementos e processos que a exprimem psiquicamente e, logo, simbolicamente. Com efeito, sem aquele fenômeno inconsciente que se desenrola no plano simbólico, expresso pela linguagem, não existiria sujeito, um sujeito que fala e, portanto, simboliza, significa, articula, ou tenta articular, um pedido de amor, ou de reconhecimento de seu próprio desejo. Onde, pois, se situa para Freud a realidade do sujeito? No inconsciente, diz Lacan. "No inconsciente, excluído do sistema do eu, o sujeito fala" (LACAN, 1978, p 77). Donde a ênfase que pôs o analista francês sobre a descoberta essencial de Freud, a qual, segundo ele, consiste justamente no descentramento do sujeito com relação ao eu (LACAN, 1978, p. 179). Mas, em última instância, não poderíamos ampliar esta questão - a do deslocamento do sujeito, de sua constante errância e, consequentemente, de sua iterativa busca do significante - para todo o campo da filosofia? No Seminário III, As psicoses, Lacan se interroga de maneira polêmica: "Não ficamos surpresos que os filósofos não tenham, desde há muito tempo, colocado o acento sobre o fato de que a realidade humana é irredutivelmente estruturada como significante?” (LACAN, 1981, p. 224).

Quanto a Freud, Lacan observa que o seu ponto de partida continua sendo, paradoxalmente, o fundamento cartesiano do sujeito da certeza. Com efeito, parodiando o filósofo francês, poderíamos reformular o cogito cartesiano dizendo: Tenho certeza de que eu duvido, de que eu penso que duvido... Similarmente, ajunta Lacan, lá onde Freud lança a dúvida, tem-se igualmente a certeza de que lá também se encontra um pensamento que é inconsciente ou, o que equivale ao mesmo, que se revela ausente. Todavia - continua a insistir Lacan - é precisamente neste lugar que Freud, ao confrontar-se com os outros, irá também evocar o "eu penso" como a condição, o caminho ou a passagem pela qual se manifestará o sujeito. Mas é também neste ponto que se produzirá este salto qualitativo: alguém pensa em seu lugar. Donde a conclusão de Lacan: a dissimetria existente entre Freud e Descartes reside não no método inicial da certeza, que é fundada sobre o sujeito, mas no fato de o sujeito freudiano pertencer essencialmente ao campo do inconsciente (Cf. LACAN, 1973, p. 36).

\section{Conclusão}

A partir dessas considerações, insinua-se inevitavelmente a questão: em Lacan, não é também a questão do fundamento do sujeito cartesiano que retorna? É bem verdade que não mais se trata - tanto em Freud quanto em Lacan - do sujeito da consciência que constrói o saber a partir de uma esfera que ele próprio se outorgara: as ideias claras e distintas. Trata-se, ao invés, como 
em Freud, de um sujeito que experienciou um salto ou, para servir-me de outra metáfora, que executou um mergulho no inconsciente. De resto, é o próprio Lacan quem o confessa: "Em primeiro lugar, a substância pensante. Pode-se, no entanto, dizer que nós a modificamos sensivelmente. Desde este eu penso que, supondo-se a si mesmo, funda a existência, tivemos de dar um passo a mais, que é o do inconsciente" (LACAN, 1975, p. 25).

Por conseguinte, o próprio Lacan vê-se igualmente obrigado a reescrever uma experiência que não pode ser dita, não pode ser lida, não pode ser significada, simbolizada ou reinterpretada, senão a partir do movimento mesmo que ele tenta superar, mas a partir de dentro. Esta dinâmica, eu a denomino - na esteira do próprio Lacan e de Roland Sublon - o paradoxo de uma exclusão interna. Efetivamente, não se trata pura e simplesmente de uma ruptura, no sentido em que haveria um corte absoluto e, portanto, uma antinomia irredutível e intransponível entre dois universos simbólicos que se teriam separado de uma vez por todas. Esta seria uma exclusão externa. Trata-se, antes, de uma ressignificação e de uma reinterpretação que se dão a partir de dentro, vale dizer, através de uma inscrição que se pontilha, se repete e se diferencia à medida mesma em que novas forças impõem novos valores, novas formas, novas qualificações, novas designações, novas denominações e, portanto, novas verdades.

De resto, que outra coisa fizeram os filósofos - de Parmênides a Heidegger, de Platão a Lévi-Strauss - senão tentar, infinita e iterativamente, estruturar a realidade humana como uma realidade significante? Se se pode, pois, falar de um fim do sujeito, este residiria na sempre terminada e sempre recomeçada tentativa de se colmatar uma hiância que não cessa de se tamponar e de se ampliar. Para dizê-lo de outro modo, o fim do sujeito consistiria na eterna tarefa de tramar, encadear, tecer, entre-tecer e apreender um significante que, todavia, continua heterogêneo, heteróclito, ex-cêntrico e recalcitrante ao pedido ou à significação enquanto tal. É que uma significação está sempre a reenviar a outra significação, uma interpretação a outra interpretação, e isto a partir de uma sensação de borda em que o sujeito não cessa de inscrever, de plasmar e remodelar o seu desejo através do simbólico do real. É esta a ambiguidade da tensão fundamental do desejo e, portanto, do sujeito que, na sua repetida dinâmica de satisfação e insatisfação, aponta para uma tendência mais elementar e mais originária ainda. Trata-se, em última instância, das forças da dispersão e da reunificação, da fragmentação e da agregação, da destruição e da construção, da aniquilação e da recriação... 


\section{Notas:}

${ }^{1}$ Doutor em filosofia pela Universidade de Metz, doutor em teologia pela Universidade de Estrasburgo. Professor de Filosofia no programa de Pós-graduação da PUCPR, professor de filosofia na FASBAM e de teologia sistemática no Claretiano - Centro Universitário. E-mail: r.mirandaalmeida@gmail.com

${ }^{2}$ As referências relativas a Platão são tiradas de:

Protagoras. In Plato in Twelve Volumes. Cambridge: Harvard University Press, 1977, v. II.

Theaetetus. In Plato in Twelve Volumes. Cambridge: Harvard University Press, 1977, v. VII.

Sophist. In Plato in Twelve Volumes. Cambridge: Harvard University Press, 1977, v. VII.

${ }^{3}$ Para os vestígios da Trindade divina no homem, veja: (AGOSTINHO DE HIPONA, 1973, XI, 1, 1). Veja também: (ALMEIDA, 2012, capítulo II, seção 1).

${ }^{4}$ Para a relação Descartes - Santo Agostinho, veja: (ALMEIDA, 2012, pp. 114-117).

${ }^{5}$ Veja, a este respeito: (ALMEIDA, 2007, caps. III e IV).

${ }^{6}$ Para a questão das várias acepções e da ambivalência que tem o conceito de vontade de potência sob a pena de Nietzsche, veja: (ALMEIDA, 2006, Cap. II, seção 3).

${ }^{7}$ Freud se referirá de novo a essas três humilhações numa das conferências (XVIII) que ele proferiu na Universidade de Viena nos invernos de 1915-1916 e 1916-1917. Essas conferências foram depois publicadas sob o título: Conferências introdutórias sobre psicanálise.

${ }^{8}$ Convém notar que Freud designa essas três instâncias do aparelho psíquico pelas palavras alemãs: Ich, Über-ich e Es.

${ }^{9}$ Veja a este respeito: (SUBLON, 2004, pp. 32-33). 


\section{Referências}

AGOSTINHO DE HIPONA. La Trinità. Roma: Città Nuova, 1973.

ALMEIDA, Rogério Miranda de. Eros e Tânatos: A vida, a morte, o desejo. São Paulo: Loyola, 2007.

. A fragmentação da cultura e o fim do sujeito. São Paulo: Loyola, 2012.

. Nietzsche and Paradox. Albany: State University of New York Press, 2006.

ARISTÓTELES. Metaphysics. 2 vol. Cambridge: Harvard University Press, 1980.

. On the Soul. Cambridge: Harvard University Press, 1975.

FREUD, Sigmund. Eine Schwierigkeit der Psychoanalyse, in Gesammelte Werke, 18 v. Frankfurt am Main: Fisher Taschenbuch, 1999, v. XII.

. Das Ich und das Es. In Gesammelte Werke, 18 v. Frankfurt am Main: Fisher Taschenbuch, 1999, v. XIII.

. Triebe und Triebschicksale. In Gesammelte Werke, 18 v. Frankfurt am Main:

Fisher Taschenbuch, 1999, v. X.

LACAN, Jacques. Le Séminaire, Livre II, Le moi dans la théorie de Freud et dans la technique de la psychanalyse. Paris: Seuil, 1978.

. . Le Séminaire, Livre III, Les psychoses. Paris: Seuil, 1981.

. Le Séminaire, Livre XI, Les quatre concepts fondamentaux de la psychanalyse.

Paris: Seuil, 1973.

. Le Séminaire, Livre XX, Encore. Paris: Seuil, 1975.

. Je parle aux murs. Paris: Seuil, 2011.

NIETZSCHE, Friedrich. Kritische Studienausgabe, 15 vol. München: De Gruyter, 1999. 
PLATÃO. Plato in Twelve Volumes. Cambridge: Harvard University Press, 1977 (Protagoras, v. II; Theaetetus, v. VII; Sophist, v. VII).

RESWEBER, Jean-Paul. Le questionnement éthique. Paris: Cariscript, 1990.

SAINT THOMAS AQUINAS. Summa contra gentiles. Notre Dame: University of Notre Dame Press, 1975.

SCHOPENHAUER, Arthur. Die Welt als Wille und Vorstellung, in Sämtliche Werke, 5 vol. Darmstadt: Wissenschaftliche Buchgesellschaft, 2004.

SUBLON, Roland. La lettre ou l'esprit: Une lecture psychanalytique de la théologie. Paris: Cerf, 1993.

. L'Éthique ou la question du sujet. Strasbourg: Éditions du Portique, 2004. 